INVESTIGACIÓN

Recibido: 12/03/2021 --- Aceptado: 12/03/2021 --- Publicado: 24/05/2021

\title{
INFLUENCERS, STORYTELLING Y EMOCIONES: MARKETING DIGITAL EN EL SECTOR DE LAS MARCAS DE MODA Y EL LUJO
}

\author{
Influencers, storytelling and emotions: digital marketing in the sector of \\ fashion and luxury brands
}

\begin{abstract}
8) Ana María Velasco Molpeceres': Universidad de Valladolid y UEMC. España. anamaria.velasco.molpeceres@uva.es
\end{abstract}

Cómo citar el artículo:

Velasco Molpeceres, A. M. (2021). Influencers, storytelling y emociones: marketing digital en el sector de las marcas de moda y el lujo. Vivat Academia. Revista de Comunicación, 154, 1-18. http:// doi.org/10.15178/va.2021.154.e1321

http://www.vivatacademia.net/index.php/vivat/article/view/1321

\section{RESUMEN}

El objetivo de este trabajo es investigar sobre las nuevas tendencias en comunicación y marketing, en concreto, en el sector de la moda y el lujo. Se estudia, a través de los perfiles de Instagram de Dior y de Chiara Ferragni, la relación entre marca e influencer y el papel del storytelling y el marketing sensorial y de emociones en el marketing de moda. La metodología seguida es el análisis de contenido, cuantitativo y cualitativo, de 12464 posts de Instagram. Los resultados de este estudio de caso evidencian el éxito de una estrategia basada en el marketing emocional y en el uso de influencers. También las diferencias entre el discurso de los influyentes y de las firmas y la necesidad de llegar a la audiencia a través de la creación de un relato, creíble, basado en la autenticidad (sea sincera o fabricada) que hace indispensable para las marcas el uso de influencers que hagan de mediadores entre su mensaje oficial y la comunidad online. No obstante, es indispensable señalar que posiblemente, a corto plazo, el influyente sea el más beneficiado por la relación con la marca y esto hace que para las firmas de moda y lujo sea necesario vigilar y controlar muy bien su política de comunicación y diseñarla pensando en el corto plazo pero también a largo plazo.

PALABRAS CLAVE: Moda - Influencer - Instagram - Marketing - Storytelling Chiara Ferragni - Branding - Marketing de influencia - Comunicación.

\footnotetext{
1 Ana María Velasco Molpeceres: doctora en comunicación por la Universidad de Valladolid, donde es profesora. También es profesora en la UEMC y la UNED. Licenciada en Periodismo, Máster en Comunicación, Graduada en $\mathrm{H}^{\mathrm{a}}$ del Arte y en Geografía e $\mathrm{H}^{\mathrm{a}}$ y Posgrado en Com. Audiovisual.
} 

lujo

\section{ABSTRACT}

The objective of this paper is to investigate new trends in communication and marketing, specifically, in the fashion and luxury sector. The relationship between brand and influencer and the role of storytelling and sensory and emotion marketing in fashion marketing are studied through the Instagram profiles of Dior and Chiara Ferragni. The methodology followed is the quantitative and qualitative content analysis of 12,464 Instagram posts. The results of this case study show the success of a strategy based on emotional marketing and the use of influencers. Also the differences between the discourse of influencers and brands and the need to reach the audience through the creation of a credible story, based on authenticity (true or fabricated) that makes essential for brands use of influencers who act as mediators between the official message and the online community. However, it is essential to point out that possibly, in the short term, the influencer will be the most benefited by the relationship with the brand and this makes necessary for fashion and luxury brands to monitor and control their communication policy very well and design it thinking in the short term but also in the long term.

KEYWORDS: Fashion - Influencer - Instagram - Marketing - Storytelling - Chiara Ferragni - Branding - Influential Marketing - Comunication.

\section{INTRODUCCIÓN}

El objetivo de este trabajo es investigar sobre las nuevas tendencias en comunicación y marketing, en concreto, en el sector de la moda y el lujo (Velasco Molpeceres, 2018; SanMiguel \& Sádaba, 2019; Pérez Curiel \& Velasco Molpeceres, 2020). Las redes sociales son una herramienta indispensable en las estrategias de comunicación empresarial, no solo al modo de complemento de los medios y la publicidad tradicional, sino como un elemento clave para llegar a la audiencia y, por ende, a los compradores. El uso de plataformas digitales como Instagram, aunque cada cierto tiempo aparecen nuevas redes: en 2020 el gran éxito fue para Tik Tok, ha supuesto en el mundo de la moda una digitalización y en particular instagramización de todo el sector, cambiando de forma importante las dinámicas del negocio.

La particularidad de la moda y del lujo es que, pese a su necesidad de jugar bajo los parámetros de buscar la viralidad en Internet, también precisan de mantener en su público la noción de exclusividad, calidad y de sofisticación, lo que choca con la democratización digital (Bastien \& Kapferer, 2012). Y además deben hacerlo en un entorno en el que su público, cliente o no, no es pasivo sino que son prosumidores (productores y consumidores en la red). Esto hace que las marcas no puedan utilizar sus perfiles de redes sociales, en particular de Instagram por ser la que privilegia la imagen, de un modo tradicional: emitiendo sus mensajes sin contar con sus seguidores. Y es por ello que han adoptado una práctica: usar influencers como un modo de mediar y dialogar con la comunidad. 


$$
\text { lujo }
$$

El uso de influencers se ha convertido así en una práctica habitual y creciente en el marketing de empresas de moda y lujo pues el objetivo es generar una comunidad de seguidores, en la que haya un importante engagement. Las redes sociales, Instagram, permiten dar visibilidad a las marcas e interactuar con un público interesado (stakeholders) que se relaciona en la red de forma natural (Monserrat-Gauchi \& SabaterQuinto, 2017; Sarmiento Guede \& Rodríguez Terceño, 2020) y que a su vez genera su propio contenido relacionado con las marcas. Pero esta práctica supone un importante desafío para las marcas de moda pues el dominio que tienen del mensaje que transmiten estos influencers en sus propios perfiles no es como el que tienen del propio perfil de la marca. Colaborar con influencers supone un traspaso de poder y surge, además, la cuestión de a quién beneficia más, pues al ser personas ajenas a la marca pueden tener intereses contrapuestos o ser difíciles de controlar (Pérez-Curiel \& Clavijo-Ferreira, 2017; Rocamora, 2017; Sanz-Marcos et al., 2020).

Es por ello que este trabajo se centra en el estudio de un caso. Analizamos dos perfiles de Instagram: el de Dior y el de Chiara Ferragni, para comprender cuál es el mensaje, el enfoque y el uso que se hace del influencer por la marca y de la marca por el influencer, estudiando las sintonías, las diferencias y las particularidades. Un elemento clave de la publicidad, que cobra un auge creciente en Internet por la dinámica transmedia del mensaje a transmitir, es es el uso de estrategias de storytelling, que permiten llegar de forma emocional a los seguidores y transmitirles la esencia, identidad y valores de la marca (González Romo \& Plaza Romero, 2017) y del influencer, pues este también articula su valor en la 'autenticidad' que transmite a su comunidad de seguidores. Y este punto va a ser fundamental en nuestro análisis, para ahondar en los motivos y en el tratamiento de los influyentes por las marcas.

La reputación digital de los influencers, con la comunidad que les sigue que genera altas tasas de interacción y engagement, es codiciada por las marcas de moda como parte de su estrategia de marketing (Castelló-Martínez, 2016; Harmeling et al., 2017; Velasco Molpeceres, 2019) y esto ha revolucionado el paradigma comunicativo del sector de las tendencias. Frente a los valores inmateriales tradicionales y de elegancia y sofisticación, exclusiva y elitista clásica, la comunicación está dominada por el presentismo, y también por lo efímero como prueba la abundancia de stories, reels, etc. (Vinader Segura et al., 2019; Segarra-Saavedra \& Hidalgo-Marí, 2018). Es por ello que la moda, y el marketing de moda, ha evolucionado a que la producción y venta de los productos del sector pase porque todo esté pensado para ser instagrameable: desfiles, campañas y diseños (Sanz-Marcos et al., 2019; Espinosa Grau, 2020; Villena Alarcón \& Fernández Torres, 2020). Y el perfil de los influyentes es fundamental (SanMiguel, 2020), aunque hay importantes diferencias de discurso entre ellos y las marcas, pues tienen objetivos diferentes.

En el caso de Chiara Ferragni y Dior la relación entre influencer y marca se ha originado a raíz de la llegada a la casa de moda de la diseñadora italiana Maria Grazia Chiuri en julio de 2016, gracias a una conexión con la italianidad que se puede apreciar en la trayectoria de la marca (por ejemplo para apoyar a Italia tras la crisis del coronavirus, en verano de 2020 se celebró en Puglia un desfile). A partir de ese año,

Vivat Academia. Revista de Comunicación. 2021, nº 154, 1-18 


$$
\text { lujo }
$$

Dior también cambió su estrategia en redes sociales, pasando a ser estas más importantes, como puede verse del aumento del número de publicaciones en Instagram. Y llegó a su máximo en primavera de 2017 cuando Chiara Ferragni protagonizó junto a la embajadora de la marca, Bella Hadid, un corto sobre maquillaje y, posteriormente, en septiembre de 2018, fecha de la boda de Chiara Ferragni con el rapero italiano Fedez, al hacerse cargo Chiuri de crear sus vestidos de boda, en un evento digital que generó tanto tráfico en Internet como la boda de los duques de Sussex, el príncipe Harry y Meghan Markle, otro momento de gran importancia en el estudio de la comunicación actual en redes (Villena Alarcón \& Segarra-Saavedra, 2020).

En torno a esos dos eventos estaba la noción de ser parte de la vida de Chiara Ferragni pues el primero apareció tras una celebración del treinta cumpleaños de la influencer que culminó con una pedida de mano pública por parte de Fedez y el segundo fue su boda, grabada en un documental (en Amazon Prime Video). Desde entonces, junto con muchas otras marcas, Dior tiene un lugar fundamental en la vida y perfil de Instagram de Ferragni pues son constantes las alusiones a su boda, aunque sin etiqueta o mención, pues sus seguidores ya saben que se asocian a la marca. Y en el perfil de Dior, Chiara tiene una presencia, pequeña, pero constante. De manera que se ha creado una interesante dinámica de relato, aunque muy diferente, que traslada el sueño de elegancia y felicidad propio de las marcas de moda al público.

\section{OBJETIVOS}

Este estudio plantea una serie de objetivos a partir de los cuales se pretende avanzar en la localización de los principales usos y nuevas tendencias en el discurso digital de la moda, en concreto, en la relación entre la marca Dior y la influencer Chiara Ferragni.

Los objetivos $(\mathrm{O})$ se concretan de la siguiente manera:

O1. Conocer qué estrategias proyectan las marcas de moda y los influencers (Dior y Ferragni) para promocionar la imagen de la marca (Dior y/o Ferragni) en Instagram, analizando si el mensaje del influencer potencia la identidad de marca de la casa o de su propia persona.

O2. Definir el relato que trasladan Dior y Ferragni, y sus colaboraciones, sobre las marcas o sobre sí mismos.

O3. Analizar las similitudes y diferencias del discurso del perfil oficial de Dior y del de Ferragni en su relación Dior-Ferragni y Ferragni-Dior.

O4. Comprobar el nivel de interacción y engagement, así como el comportamiento digital de Dior y de la influencer Ferragni, como prosumers en Instagram.

En relación a estos objetivos, se plantean las siguientes preguntas de investigación (PI):

P1. ¿Qué estrategias definen la actuación de las marcas de moda para reforzar su identidad ante la figura del influencer y ante los consumidores?

P2. ¿Cómo se relacionan la marca de moda y el influencer en la red Instagram? 

lujo

P3. ¿Prevalece el protagonismo de la identidad de la marca de moda por delante del rol del influencer o prevalece el de la influencer?

Como complemento a las preguntas de investigación, se establece asimismo una hipótesis $(\mathrm{H})$ que el análisis científico de este trabajo propone resolver.

H1. El marketing de influencia, como es denominado a veces este modelo basado en influencers (Pérez Curiel \& Luque Ortiz, 2018; Pérez-Curiel \& Sanz-Marcos, 2019), se basa en transmitir emociones, entroncando con el marketing sensorial y las últimas tendencias en neuromarketing, y de ese modo las colaboraciones entre influencers y marcas deben verse como la creación o desarrollo de una historia holística, pero transmedia y fragmentada.

\section{METODOLOGÍA}

El método propuesto para este estudio de caso se apoya en una serie de investigaciones previas basadas en el análisis de contenido comparado de indicadores cuantitativos y cualitativos (Silverman, 2016; Bryman, 2016; Franklin et al., 2015; Krippendorff, 2004; Flick, 2004). Ambos procesos constituyen la base científica de comprobación de la hipótesis general del estudio. Para ello se ha procedido al análisis de los perfiles oficiales de Instagram de Dior y de Chiara Ferragni (@dior y @chiaraferragni). Para delimitar el período cronológico de interés hemos revisado los perfiles y fijado la fecha de inicio del conteo del estudio en el año 2016, hasta el 31 de diciembre de 2020. De manera que se han analizado, a fecha de febrero de 2021, 7010 posts de Instagram para el perfil de Chiara Ferragni y 5454 posts para el perfil de Dior, es decir, un total de 12464 posts de Instagram. De ellos se ha hecho una selección, revisando que apareciera etiquetada, mencionada o en la imagen: Chiara Ferragni (o Dior en el perfil de la influencer), lo que nos ha permitido reducir la muestra a 253 posts en el caso de Ferragni y a 31 posts para Dior. Estos datos ya permiten ahondar en algunas cuestiones de los objetivos y las preguntas de investigación, en concreto en lo relativo a las estrategias de producción de contenidos. Luego, sobre la muestra concreta de los 284 posts se ha profundizado cualitativamente.

\section{RESULTADOS}

Ese estudio está determinado por la llegada de Maria Grazia Chiuri a la cabeza del diseño femenino de la casa Christian Dior. La italiana, antigua diseñadora de Valentino, fue contratada, al menos se desveló al público, en julio de 2016 $(07 / 07 / 2016)$. Ese año fue importante en la casa Dior porque desde el 11 de enero de 2016 se había aumentado el peso de la estrategia digital y del marketing en redes, en particular en Instagram, pasándose de subir más o menos una foto al día a postear tres (dado que el algoritmo hace que estas se vean de una tanda, en una misma fila, lo que permitía al community manager de Dior crear un storytelling o una identidad narrativa para cada día). Y también porque el belga Raf Simmons, que se había hecho cargo de la firma en 2012, tras un escándalo racista que internó al antiguo diseñador estrella de la casa: John Galliano, dejaba la dirección de la maison, tras años de críticas. Lo que

Vivat Academia. Revista de Comunicación. 2021, nº 154, 1-18 

lujo

suponía que Chiuri debía no solo crear una nueva identidad personal, sino conectar con el público y la clientela de Dior, una marca que iba perdiendo empuje. Esto explica la generación de un nuevo universo, fuertemente vinculado a la actualidad, tanto en lo digital (cuya potenciación venía aún de la época Simmon, si bien es cierto que del final de la misma), como a la política (y no en vano el debut de Chiuri tendrá que ver con la defensa del feminismo, gracias a unas camisetas estampadas con un lema a favor).

Tabla 1: evolución y posts por año de la relación Ferragni-Dior

\begin{tabular}{|l|l|l|}
\hline & Chiara Ferragni postea Dior & Dior acerca de Ferragni \\
\hline 2020 & 63 & 1 \\
\hline 2019 & 27 & 10 \\
\hline 2018 & 101 & 15 \\
\hline 2017 & 53 & 5 \\
\hline 2016 & 6 & 0 \\
\hline TOTAL & 253 & 31 \\
\hline
\end{tabular}

Fuente: elaboración propia

Es precisamente a partir de la llegada de Chiuri cuando Dior y Chiara Ferragni empiezan a colaborar. Primero, tímidamente, y luego uniéndose en una relación privilegiada en la que Ferragni se convierte en 'amiga de la casa', tal y como es citada cuando aparece en Instagram. La primera colaboración aparece en 2016, en el desfile de Alta Costura celebrado en julio, el mismo mes en que es contratada Chiuri, lo que indica una cierta relación, que se afianzará con el tiempo, y que se basa en la italianidad y la proximidad cultural. Sin embargo, esta no aparece aún en las redes de Dior, solo en las de Ferragni, que postea bastantes fotos del evento, tanto formales y vinculadas a Dior, como informales, lo que suele hacer y es base de su éxito.

Pero a partir de ese momento, y alcanzando su punto álgido cuando Ferragni celebre su boda con el cantante Fedez y se vista de Dior, la relación va a desarrollarse hasta que la influencer se asocie a Dior como una amiga. El año 2017 es el de colaboraciones explícitas e intensas fruto del rodaje de un vídeo con Bella Hadid sobre maquillaje, que coincidió con su treinta cumpleaños y con la pedida de mano sorpresa organizada por el rapero Fedez, lo que generó un gran volumen de tráfico, y también con un vídeo sobre el amor, poco después, que era parte de una iniciativa benéfica de Dior y Natalie Portman, embajadora y rostro de la firma.

Pero, como hemos mencionado, la relación llega a su cenit en 2018, cuando se celebra el enlace de Ferragni y Fedez, globalmente difundido bajo el hashtag \#theferragnez, aunque Dior no lo usó, tras aplazarse la boda por la maternidad de Ferragni que se quedó embarazada al poco de prometerse, en mayo de 2017. En 2019 la relación disminuye, para volver a aumentar en 2020, fruto de varios eventos de tipo personal para Chiuri y Ferragni: la mala situación de Italia durante la pandemia de coronavirus fomentó el compromiso patriótico de ambas y la celebración de varias 

lujo

actividades para difundir la cultura italiana pero también del segundo embarazo de la influencer.

Este vínculo personal y profesional, clave para generar engagement entre los influencers, evidencia el surgimiento y desarrollo también de una relación de amistad e intimidad entre Ferragni y Dior, a través de Chiuri, que se refleja en las redes de marca y persona y se desenvuelve de forma orgánica y natural. Si bien el seguimiento de los followers es mucho mayor en el caso de Ferragni, que recibe muchas más interacciones, aunque Dior tiene más de cuarenta millones de seguidores y ella solo veintisiete.

Tabla 2: Número de posts por año

\begin{tabular}{|l|l|l|}
\hline & Chiara Ferragni & Dior \\
\hline 2020 & 1576 & 1098 \\
\hline 2019 & 1387 & 1095 \\
\hline 2018 & 1347 & 1095 \\
\hline 2017 & 1369 & 1095 \\
\hline 2016 & 1331 & $1071^{*}$ \\
\hline TOTAL & 7010 & 5454 \\
\hline
\end{tabular}

Fuente: elaboración propia

Es probable que esto pueda explicarse porque la información que sube Dior en su perfil es mucho más aséptica y formal que la hiperactividad de la influencer. Dior es una marca con miles de trabajadores, que postea información de las líneas femenina, masculina, de fragancias, cosmética, de accesorios, etc., además de sobre los desfiles, campañas publicitarias, actividades y eventos varios... pero Ferragni, pese a tener un equipo de más de veinte personas, y mucho menos contenido (pues la mayor parte de lo que sube es directamente su vida privada y, sencillamente, lo que lleva puesto), genera mucho más volumen de contenidos. Ferragni publica un veinticinco por ciento más que Dior y su vida se puede seguir, además, casi en directo a través de sus stories de Instagram (aunque este tema exceda de nuestro estudio, dada la condición efímera de esos minivídeos que duran un día).

Y esto arroja luz sobre el tipo de marca generada en torno a estos usuarios individuales que han logrado ser estrellas de Internet: una vida digitalizada, nutrida tanto de lo profesional (pero que siempre se transmite como cercano y verdadero a los seguidores, que son parte de la familia del influencer) como de lo gracioso y lo íntimo, lo que genera más atracción que la información formal, aunque bella, de Dior, puesto que el usuario lo encuentra menos divertido y entra a Instagram a entretenerse. Y este entretenimiento se satisface con el storytelling vital de la influencer que es más morboso, en sentido casi voyerista, que el storytelling parcial, unidireccional, de Dior. La marca mantiene un perfil clásico, simplemente modernizado con las caras con las que colabora y con contenido audiovisual adaptado a Internet, pero continúa en sus códigos formales y serios, sofisticados, frente a la naturalidad de la influencer, que se 


$$
\text { lujo }
$$

mueve como nativa en el mundo digital, con una estrategia que no parece estratégica al público, a diferencia de la de la marca que deja claro que todo es: información, es decir, publicidad. Privilegiada, bella y moderna, pero publicidad.

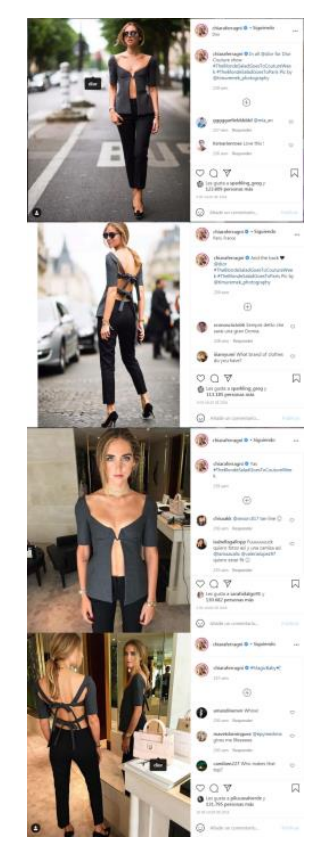

Figura 1: comienzo de la relación Ferragni-Dior (julio de 2016)

Fuente: @chiaraferragni (4/7/2016, 4/7/2016, 5/7/2016 y 18/7/2016:

https://www.instagram.com/p/BHcZXhZBN8o/, https://www.instagram.com/p/BHchOGyBjwB/, https://www.instagram.com/p/BHe0xyxh7gQ/ y

https://www.instagram.com/p/BIADuUNA5ug/https://www.instagram.com/p/ BIADuUNA5ug/)

Una vez que hemos indagado en la realidad que arroja el estudio temporal y cuantitativo de la evolución de la relación entre Dior y Ferragni, vamos a analizar la muestra específica de los 284 posts (253, Ferragni y 31, Dior). Como hemos señalado, la relación entre Chiara y Dior comienza en julio de 2016, con la llegada de la diseñadora italiana a la firma, si bien esto coincide también con la apuesta a partir de ese año de mejorar su presencia en Instagram fruto de la falta de seguimiento del Dior de Raf Simmons entre el público. Esta va a llevar a su sustitución por Chiuri, que era la diseñadora de Valentino. Inicialmente la colaboración se hace de forma tímida, solo en el perfil de Ferragni, que sube fotos patrocinadas en las que etiqueta a Dior y que parecen pactadas y formales pero también otras con amigas e incluso tiempo después que recuerdan su experiencia en el desfile de Alta Costura de Dior. Esta dinámica del recuerdo, de subir fotos antiguas, va a ser habitual en su perfil, a diferencia de en el de Dior que siempre se vincula a la actualidad de la firma (o al pasado de la misma, pero de la época de Christian Dior, en relación con algo del presente), y será fundamental porque, al encargarse la marca de su traje de novia, aunque no etiquete a Dior, toda su comunidad une su felicidad con la marca de Dior, creando un relato muy interesante 
Velasco Molpeceres, A. M.

Influencers, storytelling y emociones: marketing digital en el sector de las marcas de moda y el lujo

tanto para ella (un éxito de imagen, que refuerza su caché) como para Dior, que es recurrentemente imaginado por los seguidores de Ferragni.

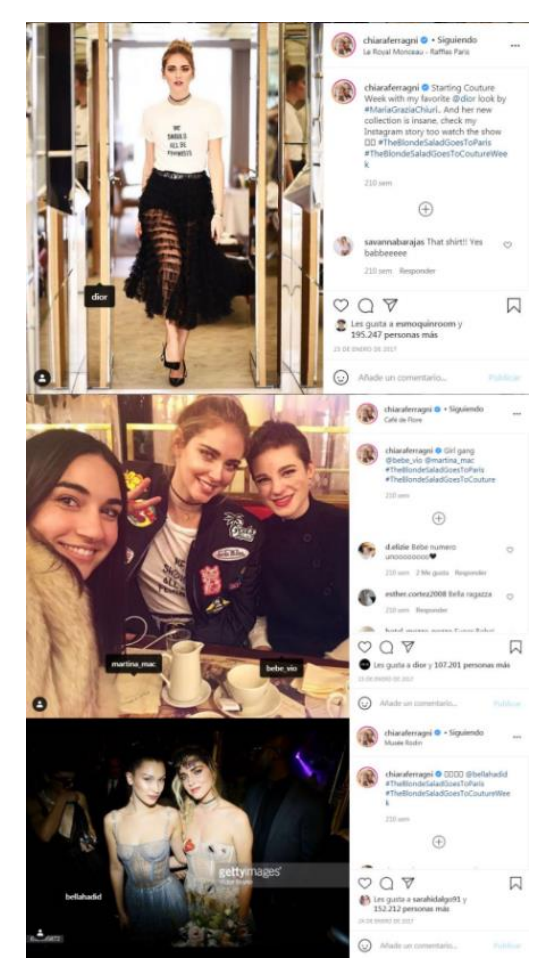

Figura 2: el año 2017 va a ser clave en la relación

Fuente: @chiaraferragni (23/1/2017, 23/1/2017 y 24/1/2017:

https://www.instagram.com/p/BPnL5Cag5H_/,

https://www.instagram.com/p/BPnXgB4gdhk/ y

https://www.instagram.com/p/BPo84PngqnC/)
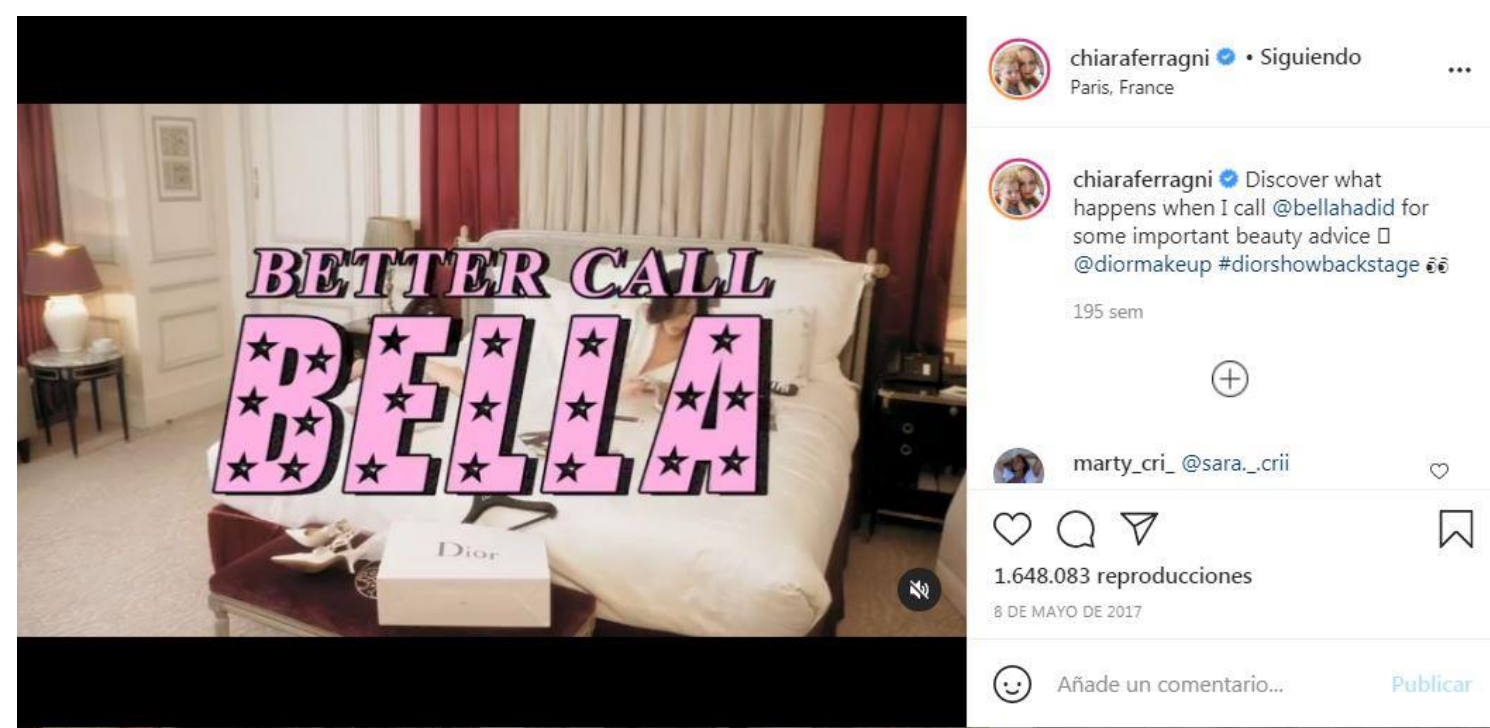

Figura 3: vídeo de Dior makeup (8/5/2017) tras prometerse y celebrar su treinta cumpleaños

Fuente: @chiaraferragni (https://www.instagram.com/p/BT01ke2DrS_/)

Vivat Academia. Revista de Comunicación. 2021, nº 154, 1-18 

lujo

A partir de 2017 el nuevo aire de Chiuri en Dior se va a hacer evidente y ese año Ferragni va a comenzar desde enero a postear y subir contenido relacionado con Dior, especialmente con la popular colección de Chiuri en la que aparecían camisetas con mensaje feminista. Sin embargo, pronto la relación va a caminar hacia lugares más personales, dejando Chiara Ferragni su condición de voz digital (comienza haciéndose cargo en un desfile del Snapchat), de mujer atractiva luciendo ropa bonita, para pasar a ser una figura con voz propia en el universo de Dior. Aunque aún la italianidad no tiene demasiada presencia en la relación Chiuri-Chiara, paulatinamente esta va a ser mayor, llegando a su cénit en 2020, por la crisis del coronavirus. Sin embargo, en este año ya empieza a cobrar un tono personal que paulatinamente va a hacer que Dior sea un elemento recurrente en la vida íntima de Ferragni y de su comunidad de fieles, aunque el número de publicaciones en Dior no sea tan alto sí que va a ser cualitativamente destacado desde su unión a su historia de amor con Fedez que acaba en boda y maternidad.

La primera gran muestra de interés de Dior-Ferragni va a ser el rodaje de un vídeo sobre maquillaje en el que Ferragni aparece con una embajadora de la marca, la supermodelo Bella Hadid, y posa en un evento en enero de 2017 que luego fructificará en un spot publicitario: https://www.instagram.com/p/BT01ke2DrS_/ Este se va a lanzar justo después de una fiesta organizada por la propia Ferragni: con motivo de su 30 cumpleaños organizó una celebración por Italia en la que con sus amigos se dedicaba a disfrutar de la vida y del éxito. La gira acabó con la proposición de Fedez en un concierto, que ella aceptó, el siete de mayo de 2017, y al día siguiente, con todo el tráfico generado, Ferragni subió el vídeo de su colaboración.

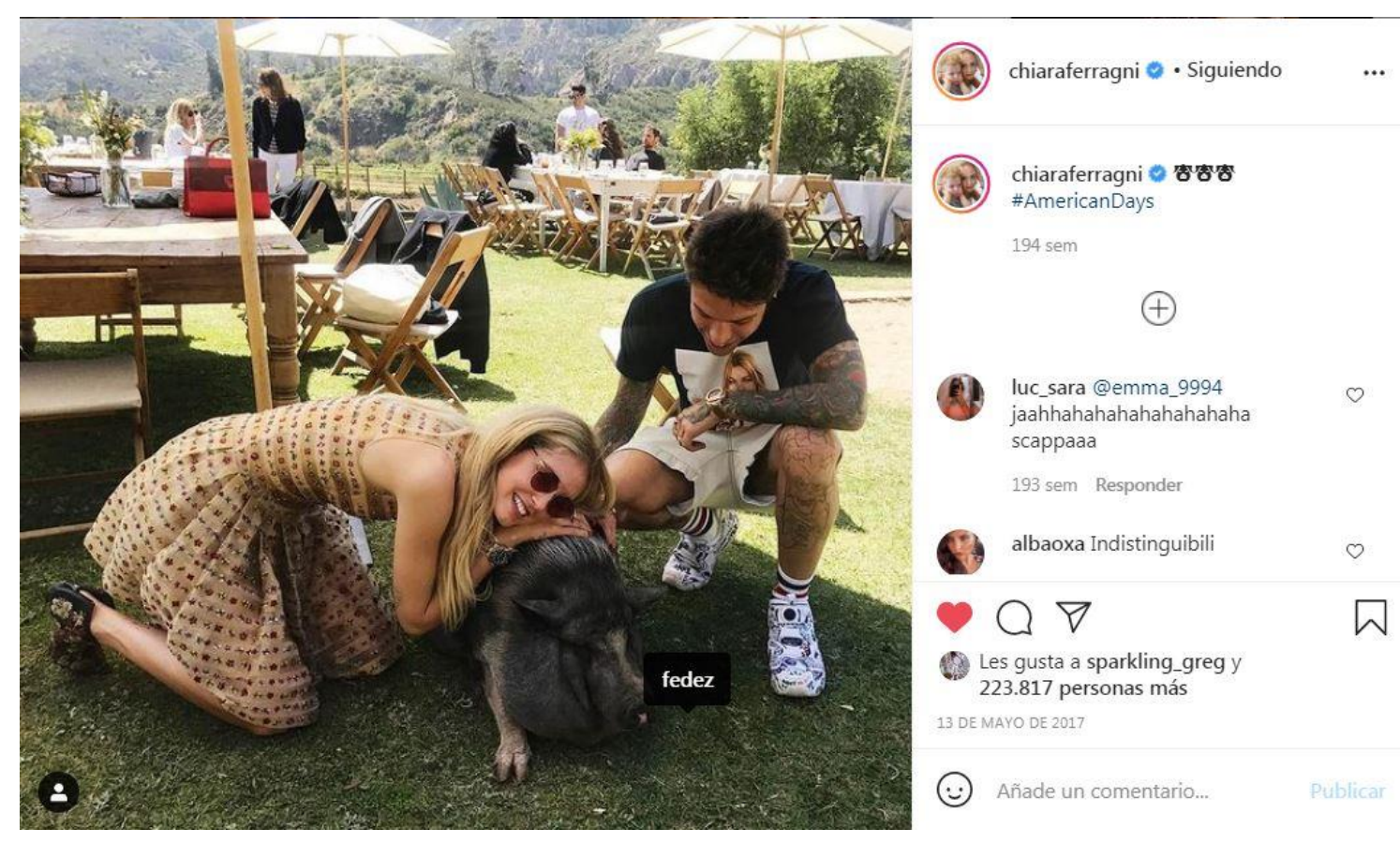

Figura 4: desfile de Dior, crucero (13/5/2017)

Fuente: @chiaraferragni (https://www.instagram.com/p/BUCiHGtDPWZ/) 
Al que siguió un traslado a Estados Unidos para, con su prometido, ir a ver un desfile de Dior, en el que posó en el photocall, sin demasiada trascendencia en Dior, más allá de la foto de rigor luciendo el traje, pero que fue muy seguido por sus seguidores. Junto a las imágenes patrocinadas, con la etiqueta a Dior y el agradecimiento, vestida por la firma, Ferragni subió fotos graciosas con Fedez, muy apreciadas por sus seguidores que querían saber más de la vida de la pareja recién prometida. En Dior la historia de amor les debió interesar, sobre todo por la atención en Internet que generaba, porque en agosto de 2017 escogieron a la pareja para protagonizar uno de los vídeos de una campaña benéfica, organizada por Natalie Portman, en la que reflexionaban sobre el amor. El tono de la misma, en blanco y negro, era informal pero dentro de los cánones de Dior. Sin embargo, en el perfil de Ferragni se podía seguir la intimidad de la pareja de otra manera, más divertida y fresca, aunque aún no se sabía que estaba embarazada, pues lo harían público a los cinco meses. Esto llevo a retrasar el enlace pero también a que el mismo tuviera mucho más eco.

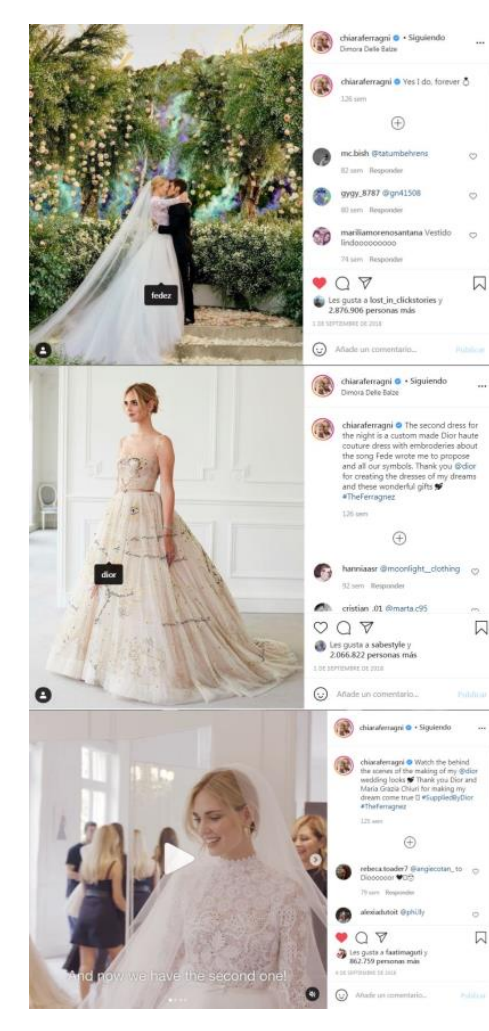

Figura 5: boda en el perfil de Chiara

Fuente: @chiaraferragni (1/09/2018, 1/09/2018 y 06/09/2018:

https://www.instagram.com/p/BnMVJUNHHpX/, https://www.instagram.com/p/BnMicupnxYR/ y https://www.instagram.com/p/BnZNmjKnnyV/) 

lujo

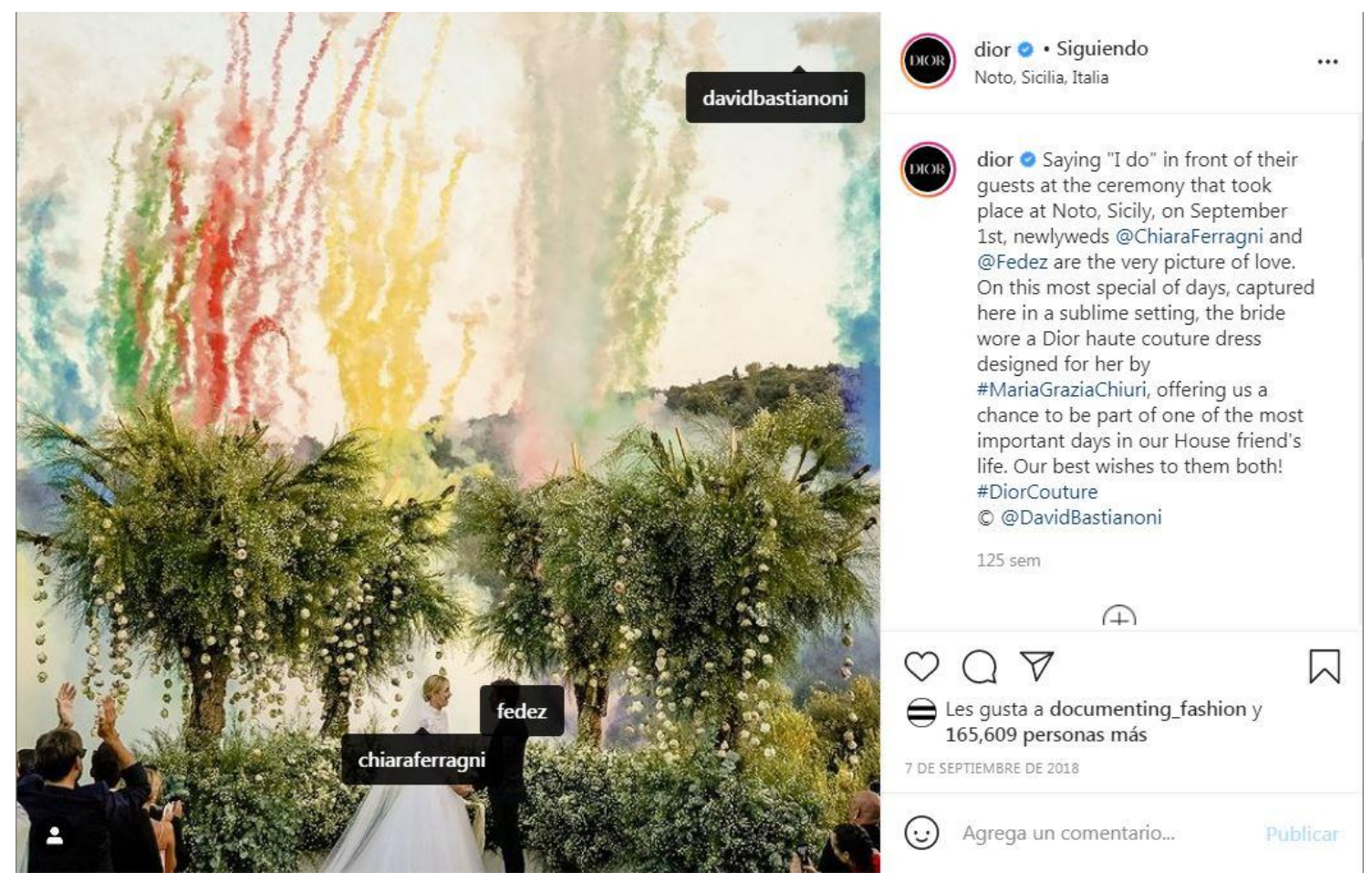

Figura 6: la boda en Dior Fuente: @Dior

La relación con Dior continuó, con apariciones pagadas en eventos, pero se hizo especialmente fuerte en 2018 cuando un día antes de la boda (1/09/2018) Ferragni desveló que Chiuri para Dior se hacía cargo del diseño del vestido. En Dior postearon nueve imágenes de la boda, una cifra sin precedentes, y Ferragni convertiría el enlace en un acontecimiento mediático mundial que, además, refresca constantemente en su perfil. La mayoría de imágenes de Dior que sube son precisamente de su boda y, aunque no etiqueta a Dior, es considerada 'amiga de la casa' y sus seguidores no pueden obviar la relación entre su intimidad y la marca. El storytelling vital que nos traslada constantemente es su felicidad, que plasma en su boda, y eso se asocia a Dior.

Es cierto que en Dior Chiara no es un rostro a la altura de sus grandes estrellas: Charlize Theron, Natalie Portman, Cara Delevigne, Rihanna o Johnny Depp, pero tampoco es una famosa más. Así ha alcanzado el estatus de amiga de la marca, al tiempo que en su propio perfil es una especie de Cenicienta, tocada por el hada madrina de la elegancia de Dior, lo que beneficia su prestigio y hace que los seguidores vean a Dior de forma privilegiada, incluso sin mencionarse. Esta parece una relación fructífera para ambas marcas, si bien es posible pensar que el beneficio a corto plazo es mayor para Ferragni que para Dior pues sus seguidores la asocian a los valores inmemoriales de Dior mientras que para la firma es una forma de modernizarse, pero no una parte clave de su identidad o de su historia. 

lujo

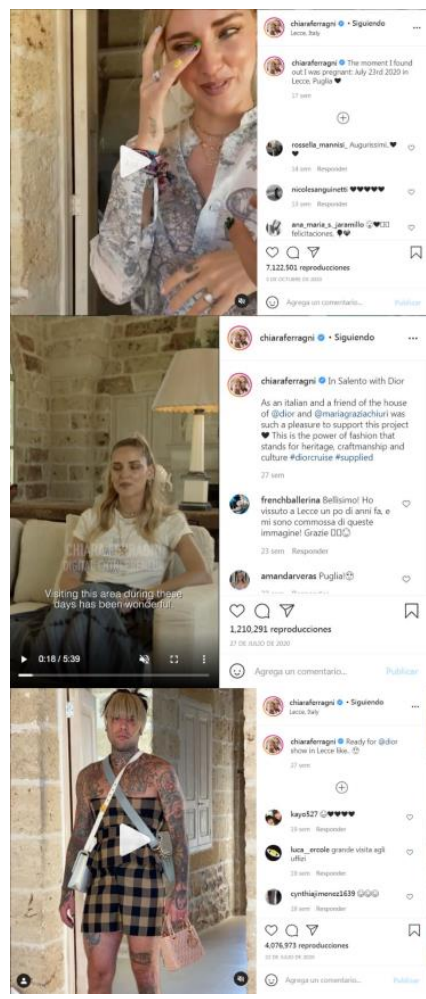

Figura 7: la madre Italia (Chiara y Chiuri en Dior)

Fuente: @chiaraferragni (3/10/020, 27/7/2020 y 22/7/2020:

https://www.instagram.com/p/CF4R-5FKFfm/, https://www.instagram.com/p/CDJWQXQKUjs/ y

https://www.instagram.com/p/CC8_uqGqAu7/)

Esta diferencia (para Ferragni Dior es una parte vital en su historia personal, y en el storytelling que conocen sus seguidores, pero para Dior Chiara es solo una 'amiga' en un universo con otros rostros más importantes) se puede ver en toda la relación que mantienen en los perfiles de Instagram. Y explica también la diferencia del tono de sus publicaciones: informales y divertidas, personales, en el de Ferragni y profesionales y educadas en el caso de Dior. No obstante, dentro de la relación personal entre influencer y marca, cabe mencionar que el vínculo entre Chiuri y Chiara se ha ido estrechando y así se puede ver en la recurrente presencia de Ferragni en las actividades de Dior.

La crisis del coronavirus de 2020, que golpeó con especial fuerza a Italia, supuso un nuevo momento de inflexión en la relación pues Ferragni y Fedez concienciaron de la pandemia y recaudaron dinero para la misma en el tiempo del confinamiento, motivo por el que fueron reconocidos en Milán, adonde acudieron vestidos de Dior. Para el verano se comprometieron a viajar por Italia para apoyar la recuperación económica de su país y ha sido ese objetivo el que les ha vuelto a unir a Chiuri, que de origen italiano, organizó un desfile en Puglia y diversas actividades vinculadas a Dior. En ellas Ferragni vuelve a aparecer como 'amiga' de la casa, como ella misma se define, difundiendo la italianidad y la cultura italiana en una casa tradicionalmente vinculada a Francia como es Dior, pero cuyo origen común con Chiuri la sitúa en una nueva esfera de influencia. 
Por otra parte, esta historia personal de lo italiano y el coronavirus se funde con otro momento estelar en la vida de Ferragni, seguido casi en directo por sus seguidores: su segundo embarazo que, como dio a conocer en octubre, conoció precisamente mientras asistía al desfile en Puglia de Dior, en julio, y así lo comparte en sus redes: vestida de Dior y llorando al ver el resultado positivo en el test.

Es otro momento que une a Ferragni con Dior, en su perfil persona, aunque en las redes de la marca sea solamente una amiga querida, muy querida de Chiuri, como puede verse en su perfil personal de Instagram y en las primeras imágenes colgadas en 2021 en las que vuelve a aparecer Ferragni, recordando su amistad en la boda y simplemente luciendo un bolso, prueba de que los vínculos personales del perfil de la influencer van paulatinamente calando en Dior. También la propia Ferragni se permite más confianzas con Dior, como puede verse en el vídeo de su marido vestido con ropa femenina que subió en julio, y en las imágenes y comentarios en los que menciona a Chiuri, lo que aventura que la relación continuará y se desarrollará. Esto permite reflexionar sobre la influencia creciente de las dinámicas de los influencers en los perfiles de las grandes marcas, atraídos precisamente por el engagement con sus seguidores.

\section{DISCUSIÓN}

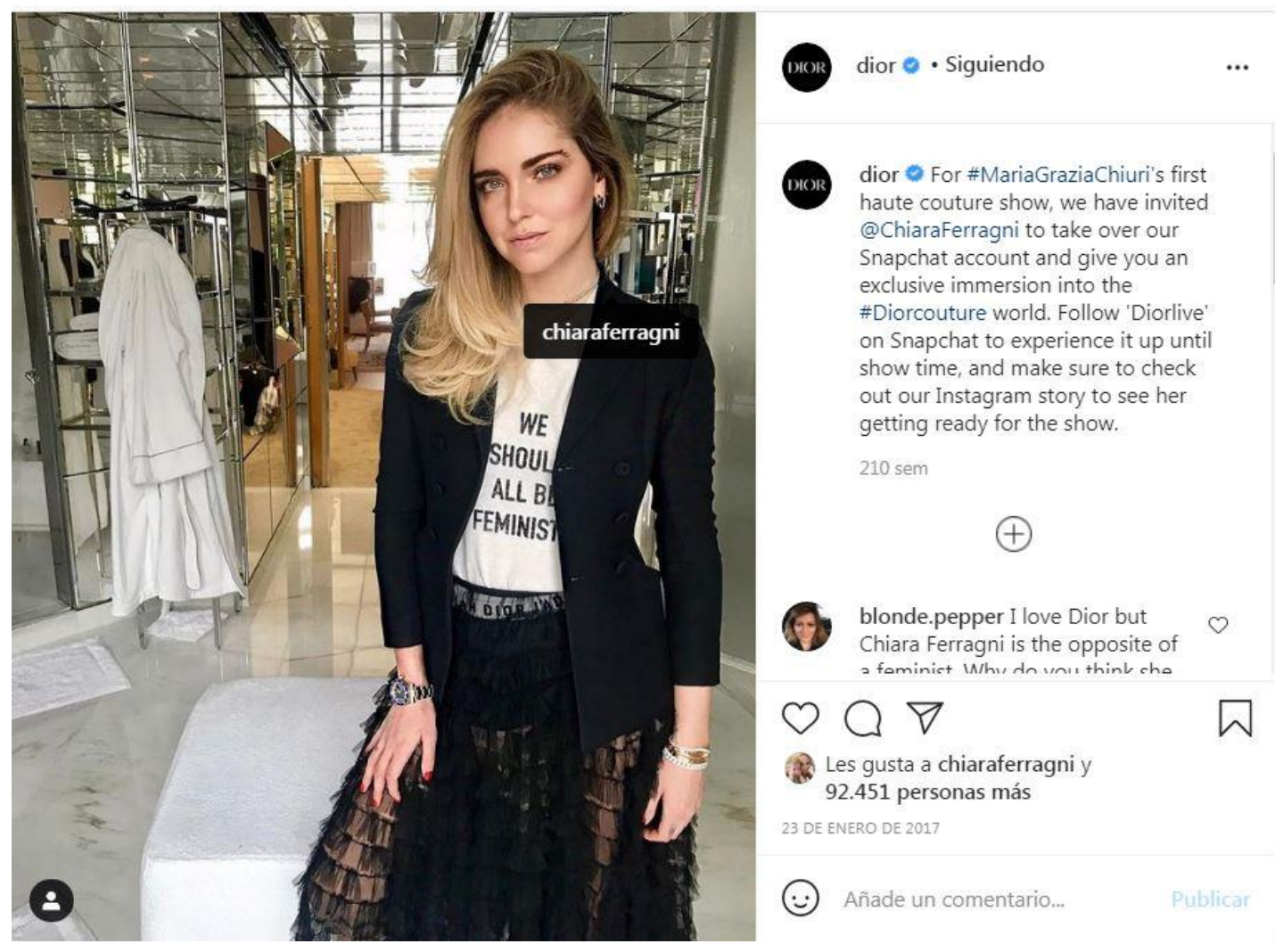

Figura 8: 23/1/2017 Chiara controla Snapchat para el primer desfile HC de Chiuri Fuente: @Dior (https:/ / www.instagram.com/p/BPm4C1jA7kb/) 

lujo

Tal y como planteábamos, este estudio ha constatado la fructífera relación entre una marca del sector de lujo y una influencer, aun cuando es probable que sea Ferragni la más beneficiada por el nexo de su persona con Dior. Sin embargo, paulatinamente, al entrar la marca en su esfera de discurso: en lo espontáneo, lo familiar y lo íntimo, la relación con los seguidores se enriquece y se mejora el engagement al reducirse la percepción de 'publicidad' o 'información oficial' del perfil. El vínculo con Ferragni tiene que ver con la personalidad del Dior actual, vinculado a la italiana Maria Grazia Chiuri, y es probable que sea solo válido en ese contexto de italianidad, pues cada diseñador estrella debe implantar su personalidad en la casa que dirigen. Es por ello que consideramos que la relación entre el Dior de Chiuri y la influencer Ferragni es beneficiosa para ambos pues contribuye a un relato italianizante y personal de Dior desde la llegada de Chiuri en julio de 2016. La trayectoria de ambas mujeres, diseñadora e influencer, es paralela en sus marcas pues ha ido consiguiendo paulatinamente mayor repercusión.

Y podemos constatar que el vínculo se ha hecho de forma natural, siguiendo los eventos de la vida de Ferragni, de manera que es percibido como auténtico por la comunidad de seguidores. De los tímidos inicios como voz digital que llegó a hacerse cargo del perfil de Snapchat de Dior en el primer desfile de Chiuri, ambas han forjado un vínculo rastreable sobre todo en el perfil de Chiara, por ser este personal, pero que también se va haciendo visible en Dior. De hecho es la única influencer, nativa digital, con la que la casa tiene una relación personal, que la moderniza. No obstante, serán necesarios más estudios en el futuro para saber la deriva de este vínculo, si se mantiene ya que sigue Chiuri o si desaparece estando o no Chiuri.

En relación con los objetivos de la investigación podemos, pues, concluir que en lo tocante al objetivo 1 (O1) la estrategia que utiliza la marca Dior y la marca Ferragni para promocionar el producto de Dior es diferente pues uno se centra en lo formal y la otra en lo íntimo, si bien la segunda está influenciando las actividades de Dior. En lo tocante al objetivo $2(\mathrm{O} 2)$, que se preguntaba por el relato que trasladaban Dior y Ferragni en sus colaboraciones, podemos decir que es el mismo: la elegancia y la felicidad, aunque el perfil de Ferragni es más numeroso en publicaciones y mucho menos serio, centrándose en Dior pero a través de ella. En Dior todo es menos personal, aunque como hemos dicho en el año 2020, con la crisis del coronavirus, esto se diluye. En lo que respecta al objetivo $3(\mathrm{O} 3)$ concluimos que las diferencias son el enfoque: informativo o íntimo, aunque trasladar un mundo de sueños es el elemento común a ambos perfiles. Y en lo relativo a la interacción y el engagement (O4) el de Ferragni es mayor y probablemente por ello, por ser su lenguaje más cercano al que se desea en Internet, las colaboraciones han ido creciendo.

En conclusión, para responder a las preguntas de investigación que hacíamos, aseveramos que la marca Dior siempre aparece como el elemento fundamental en su perfil pero en el de Ferragni es como parte de su familia, lo que ha provocado que acabe siendo etiquetada como 'amiga de la casa' en el propio perfil de Dior, ahondando paulatinamente en lo fresco de su perfil, aunque aún formal. En lo referido a la 

lujo

pregunta dos, como la relacionan de la marca de moda y el influencer en Instagram, concluimos que lo han hecho orgánicamente y que por ello probablemente la relación haya sido tan exitosa pues los seguidores perciben el vínculo Ferragni-Chiuri/Dior como natural, no prefabricado. En lo relativo a la pregunta tres, si prevalece el protagonismo de la identidad de la marca de moda por delante del rol del influencer o, por el contrario, prevalece el de la influencer, creemos que es difícil constatar cuál prima aunque es probable que la imagen de Ferragni sea la más reforzada porque Dior es una marca más consagrada que la suya propia, imbricando su propia vida en la esfera del lujo de Dior. Y esto confirma también la hipótesis de la investigación pues la vida de Ferragni es eco del sueño que vende Dior, en todos sus productos, líneas y publicaciones, encontrando a su vez este discurso personal una retroalimentación en el perfil de Dior. No obstante, debemos señalar que este trabajo es un estudio de caso por lo que es necesario comprender las limitaciones del estudio para plantear conclusiones generalizables.

\section{REFERENCIAS}

Bastien, V. \& Kapferer, J. N. (2012). The Luxury Strategy: Break the rules of marketing to build luxury brands. Kogan Page

Bryman, A. (2016). Social research methods. Oxford University Press.

Castelló-Martínez, A. (2016). El marketing de influencia: Un caso práctico. En Tendencias publicitarias en Iberoamérica: Diálogo de saberes y experiencias (pp. 49-65). Colección Mundo Digital. http://dx.doi.org/10.14198/MEDCOM/2016/8

Espinosa Grau, A. (2020). La instagramización de los desfiles de moda en tiempos de hipermodernidad: era del directo y última temporada 2020. Redmarka. Revista de Marketing Aplicado, 24(2), 110-128. https://doi.org/10.17979/redma.2020.24.2.7073

Flick, U. (2004). Introducción a la metodología cualitativa. Ediciones Morata.

Franklin, B., Hamer, M., Hanna, M., Kinsey, M., \& Richardson, J. E. (2015). Key concepts in journalism studies. Sage.

Harmeling, C. M., Moffett, J. W., Arnold, M. J. \& Carlson, B. D. (2017). Toward a theory of customer engagement marketing. Journal of the Academy of marketing science, 45(3), 312-335. https://doi.org/10.1007/s11747-016-0509-2

Krippendorff, K. (2004). Análisis de contenido: Una introducción a su metodología. SAGE.

Monserrat-Gauchi, J. \& Sabater-Quinto, F. (2017). Planificación estratégica de la comunicación en redes sociales. UOC. 
Influencers, storytelling y emociones: marketing digital en el sector de las marcas de moda y el lujo

Pérez-Curiel, C. \& Clavijo-Ferreira, L. (2017). Comunicación y Social Media en las Empresas de Moda. Revista Prisma Social, (18), 226-258. https://revistaprismasocial.es/article/view/1440

Pérez-Curiel, C. \& Luque-Ortíz, S. (2018). El marketing de influencia en moda. Estudio del nuevo modelo de consumo en Instagram de los millennials universitarios. adComunica. Revista Científica de Estrategias, Tendencias e Innovación en Comunicación, 15, 255-281. http://dx.doi.org/10.6035/2174-0992.2018.15.13

Pérez-Curiel, C. \& Sanz-Marcos, P. (2019). Estrategia de marca, influencers y nuevos públicos en la comunicación de moda y lujo. Tendencia Gucci en Instagram. Prisma Social, (24), 1-24. https://revistaprismasocial.es/article/view/2826

Pérez Curiel, C. \& Velasco Molpeceres, A. M. (2020). Nuevas narrativas del marketing de influencia en moda. Perfiles profesionales y modelos de consumo. Revista de Marketing Aplicado, 24(2), 1-9. https://doi.org/10.17979/redma.2020.24.2.7322

Rocamora, A. (2017). Mediatization and Digital Media in the Field of Fashion. Fashion Theory, 21(5), 505-522. https://doi.org/10.1080/1362704X.2016.1173349

SanMiguel, P., \& Sádaba, T. (2019). Consumo de información de moda entre los/as millennials. Revista Prisma Social, https://revistaprismasocial.es/article/view/2840

SanMiguel, P. (2020). Influencer Marketing: Conecta tu marca con tu público. Lid.

Sanz-Marcos, P., Jiménez-Marín, G. \& Elías Zambrano, R. (2019). La incorporación de la figura del influencer en las campañas publicitarias: Consecuencias para las agencias de publicidad españolas. adComunica, (18), 6386. http://dx.doi.org/10.6035/2174-0992.2019.18.5

Sanz Marcos, P., Pérez Curiel, C. \& Velasco Molpeceres, A. M. (2020). Hacia un cambio en el sector de moda y lujo. Del dominio del influencer a la marca: Gucci, Loewe y Margiela. Revista de Comunicación, 19(2), 263-284. $\underline{\text { http:/ / dx.doi.org/10.26441/rc19.2-2020-a15 }}$

Sarmiento Guede, J. \& Rodríguez Terceño, J. (2020). La comunicación visual en Instagram: estudio de los efectos de los micro-influencers en el comportamiento de sus seguidores. Estudios sobre el mensaje periodístico, 26(3), 1205-1216. https://doi.org/10.5209/esmp.65046

Segarra-Saavedra, J. \& Hidalgo-Marí, T. (2018). Influencers, moda femenina e Instagram: el poder de prescripción en la era 2.0. Revista Mediterranea de Comunicación, 1(9), 313-325. https:/ / doi.org/10.14198/MEDCOM2018.9.1.17

Silverman, D. (2016). Qualitative research. Sage Publication. 
Influencers, storytelling y emociones: marketing digital en el sector de las marcas de moda y el lujo

Velasco Molpeceres, A. M. (2018). Presentación dossier moda y comunicación. Revista internacional de Historia de la Comunicación, (10), 1-7. https://hdl.handle.net/11441/78843

Velasco Molpeceres, A. M. (2019). La moda en los medios de comunicación: de la prensa femenina tradicional a la política y los/as influencers. Revista Prisma Social, (24), 153-185. https://revistaprismasocial.es/article/view/2845

Villena Alarcón, E. \& Fernández Torres, M. J. (2020). Relaciones con los públicos a través de Instagram: los influencers de belleza como caso de estudio/Beauty on Instagram: Relations between influencers and the stakeholders. Revista Internacional de Relaciones Públicas, 10(19), 111-132. http:/ / dx.doi.org/10.5783/RIRP-19-2020-07$\underline{111-132}$

Villena Alarcón, E. \& Segarra-Saavedra, J. (2020). Engagement, redes sociales y moda internacional. La boda real de Harry-Meghan Markle. Revista de Comunicación, 19(2), 303-318. https://doi.org/10.26441/RC19.2-2020-A17

Vinader-Segura R, Vicente-Fernández, P. \& Gallego-Trijueque S. (2019). La comunicación de Moda en Youtube. Análisis del Género Haul en el caso de Dulceida. Revista Prisma Social, $\quad$ (24), 78-98. https://revistaprismasocial.es/article/view/2828

\section{AUTOR/ES:}

\section{Ana María Velasco Molpeceres}

Ana María Velasco Molpeceres es doctora en comunicación por la Universidad de Valladolid, donde es profesora. También es profesora en la UEMC y la UNED. Licenciada en Periodismo, Máster en Comunicación, Graduada en Historia del Arte y en Geografía e Historia y Posgrado en Comunicación audiovisual. Está especializada en moda, identidades en los medios de comunicación, comunicación política, influencia, nuevas narrativas digitales y efectos, así como historia de la comunicación y estudios de género. Entre sus publicaciones destacan trabajos en revistas científicas como Historia y comunicación social, Prisma social, Observatorio, Revista Latina o Revista de Occidente, así como varios libros.

anamaria.velasco.molpeceres@uva.es

Orcid ID: http://orcid.org/0000-0002-0593-0325

Google Scholar: https://scholar.google.com/citations?user=xPnUDmUAAAAJ

Academia.edu: https://uva-es.academia.edu/AnaVelasco 